\title{
Stanley Kubrick y Jean Renoir: Dos miradas fílmicas a la Gran Guerra
}

\author{
Carmen MarTA-Lazo \\ Universidad de Zaragoza \\ cmarta@unizar.es \\ José Antonio Gabelas BARroso \\ Universidad de Zaragoza \\ jgabelas@unizar.es \\ Miguel Angel OrTiz Sobrino \\ Universidad Complutense de Madrid \\ maortiz@ucm.es
}

Recibido: 20 de junio de 2013

Aceptado: 2 de julio de 2013

\begin{abstract}
Resumen
Hace un siglo que dio comienzo la I Guerra Mundial, conocida hasta 1939 como la Gran Guerra. Este primer gran conflicto bélico del pasado siglo que se saldó con la muerte de más de nueve millones de combatientes ha sido argumento de muchas obras cinematográficas producidas sobre todo en América y Europa. Entre ellas, la obra de Stanley Kubrick "Senderos de gloria" y el film de Jean Rennoir "La gran ilusión". Se trata de dos obras cinematográficas antibelicistas que ofrecen una visión de la guerra desde ópticas diferentes. Una desde la perspectiva del campo de batalla y la otra desde una óptica menos visceral de los conflictos armados.
\end{abstract}

Palabras clave: Gran Guerra; Renoir; Kubrick; conflicto mundial; cine; Primera Guerra Mundial.

\section{Stanley Kubrick y Jean Renoir: Two looks filmic to the Great War}

\begin{abstract}
A century ago that started World War I, known until 1939 as the Great War. This first major war of the last century that resulted in the deaths of more than nine million combatants has been argument produced many films especially in America and Europe: Among them, the work of Stanley Kubrick "Paths of Glory" and Jean Renoir film "The Great Illusion". These are two antiwar films that offer a view of the war from different perspectives. One from the perspective of the battlefield and the other from a less visceral optical armed conflict.
\end{abstract}

Keywords: Great War, Renoir, Kubrick, global conflict, film, First World War

\section{Referencia normalizada}

Marta-Lazo, C., Gabelas Barroso, J. A. y Ortiz Sobrino, M. A. (2013) Stanley Kubrick y Jean Renoir: Dos miradas fílmicas a la Gran Guerra. Historia y Comunicación Social. Vol. 18, págs. 157-167. 
Sumario: 1. Introducción: El cine y I Guerra Mundial. 2. Estado de la cuestión y Marco contextual. 3. Metodología. 4. Dos miradas fílmicas a la I Guerra Mundial: "Senderos de gloria" (Stanley Kubrick, 1957) y "La gran ilusión” (Jean Renoir, 1937). 5. Conclusiones. 6. Bibliografía.

\section{Introducción: El cine y la I Guerra Mundial}

Dice Quijano Ramos (2011) que casi 100 años después del comienzo de la I Guerra Mundial, la que fue denominada como la Gran Guerra es todavía un eslabón esencial para comprender el mundo actual. A lo largo de este tiempo, este conflicto bélico en el que perecieron más de nueve millones de combatientes ha sido abordado, desde diferentes puntos de vista, en una amplia producción científica. La visión general del conflicto (Howard, 2003), el uso de la propaganda en la contienda (Sánchez Medero, 2008) o la influencia de la Gran Guerra en la construcción del status quo de las relaciones internacionales (Sanz Díaz, 2009), son algunas de las perspectivas afrontadas en las diferentes aportaciones bibliográfica. Incluso, las causas de la contienda han sido también motivo de reflexión por parte del poder eclesiástico (Fazio, 2009). En todo caso, son tantas las contribuciones al estudio de este conflicto, a lo largo del siglo XX y XXI, que relacionarlas en un artículo sería una empresa prácticamente imposible. Sin embargo, no se trata de mencionar y clasificar las múltiples aportaciones científicas sobre el tema, sino poner de manifiesto la existencia de diferentes ópticas (Ramírez Benito, 2010) de esta Gran Guerra que, sin duda, marcó el orden mundial del Siglo XX, así como analizar el reflejo que de ella hicieron dos grandes directores - Stanley Kubrick y Jean Renoir- en sus obras "La gran ilusión" y "Senderos de Gloria".

\section{Estado de la cuestión y marco contextual}

A efectos de contextualizar la visión que de la Gran Guerra trasladan Renoir y Kubrick en las dos obras objeto de este análisis, interesa conocer sobre todo en qué medida la I Guerra Mundial ha sido objeto del séptimo arte. Comenta Pizarroso (1998) que la guerra como crisol de las pasiones humanas ha sido uno de los temas favoritos de los cineastas de todos los tiempos y de todas las latitudes. Al mismo tiempo, la Guerra también valora el cine como medio de comunicación y poderosa arma tecnológica que sirve a los propios intereses y la capacidad del cine para proporcionar noticias o imágenes espectaculares de la guerra tiene mayor verosimilitud que cualquier otro medio (Lathman, 2006: 36).

Hoy se pueden encontrar estudios genéricos sobre la historia del cine que incluyen el periodo en el que situamos nuestro análisis (Cousins, 2008; Talens \& Zunzunegui, 1998; Jeanne \& Ford, 1984; Gubern, 1971). Además, existe bibliografía en relación con el tratamiento que el cine ha dado a este conflicto bélico desde diferentes puntos de vista, como el americano (Guerra Gómez y Tajahuerce, 1995), el histórico 
(Coronado Ruiz, 2010 y Barroso, 2013) y sobre los directores objeto de este artículo (Flores Auñón, 1981; García Fernández y Sánchez González, 2001), entre otros.

\subsection{La industria cinematográfica en el contexto histórico de la Gran Guerra}

Algunos autores señalan la década de 1910 como el momento en el que se asienta la industria cinematográfica como consecuencia de la I Guerra Mundial, dado que los países otorgaron al cine un papel importante como instrumento propagandístico (Porter y González, 1988: 23). Sin embargo, aunque el cine fue utilizado para grabar las atrocidades producidas en los campos de batalla, la industria cinematográfica sufrió también los efectos de la guerra (Muñoz Suay, 2013). Su producción decayó como consecuencia de la movilización militar de los profesionales del cine, al tiempo el público abandonaba las salas de proyección ante la conmoción del terrible conflicto. La poca industria que sobrevivió se puso muy pronto al servicio de la victoria final. En cualquier caso, lo que si parece cierto es que el cine sobre la Gran Guerra marca el comienzo del cine bélico y propagandístico (Romero, 2013), si bien la utilización y el desarrollo del cine no es igual en todos los países (Korte ,1997: 351).

Antes del comienzo de la Gran Guerra, en los países aliados ya se habían realizado algunas producciones con tono belicista, denominadas "filmes de hunos", en las que se ridiculizaba a los alemanes y los exhibía como verdugos en la guerra franco-prusiana como, por ejemplo, "El abuelo" (Pathé, 1909). A partir de 1914, son varias las películas en esta clave antigermánica que se producen en Europa: "La venganza belga" (Francia, 1914), "El juicio de Dios" (Estados Unidos, 1914) y "La venganza del gurka" (Gran Bretaña, 1915), entre otras. También como filmes que auguraban la cercanía de la contienda, podemos citar la francesa "Alerté" (George Pallu \& E. Berny, 1912) y la británica "Si Inglaterra fuera invadida" (Fred Durrant, 1914). De manera opuesta, también se encuentran ejemplos de filmografía pacifista, como la franco-belga "Maldita sea la guerra" (Alfred Machin, 1912) o "Abajo las armas" (Holger-Madsen, 1915). En Italia, a pesar de la guerra, la industria cinematográfica continuó produciendo largometrajes histórico-belicistas, como "En el hogar extranjero"(1914), "Siempre adelante, Saboya" (1915), "Italia se despierta" (1915) y "Los horrores de la guerra" (1916).

En el caso de Alemania, la situación era diferente por aquella época. Como concluye Gertraude Bub, el convencimiento alemán de su superioridad para ganar la guerra hizo que no consideran tan siquiera la importancia de la propaganda cinematográfica (cit. Romero, 2013). En el país germano, durante el primer invierno de la guerra cuando los militares y la población civil pensaban que el triunfo estaba próximo, llegaron a las carteleras películas ubicadas en una "ambientación gris militar", tales como "La navidad de Michel", "Sueño navideño de un reservista", "El sueño en la noche de Navidad", "Año nuevo en las trincheras" o "Campanas navideñas, de 1914" (Korte, 1997). También se proyectaron filmes que personalizaban diferentes situaciones en el contexto bélico, tales como "Mujeres alemanas, fidelidad alemana" 
(1914), "Matrimonio de guerra" (1914), "Tiene que ser toda Alemania" (1914) o "Héroes alemanes" (1914). Todas ellas tendrán en común el espíritu hacia la victoria que hacía que se unificasen clases y se disipasen las diferencias sociales, en sacrificio por Alemania.

Cuando el conflicto pasó a convertirse en una guerra de trincheras con gran cantidad de muertos, los alemanes volvieron a demandar de nuevo comedias alejadas de los temas militares. Como consecuencia, el Ministerio de Guerra prohibió este tipo de películas consideradas frívolas y no "adecuadas para los graves tiempos actuales, bajo amenaza de drásticas medidas punitivas" (Korte, 1997: 356). Por su parte, los dirigentes políticos y militares, conforme avanzaba la guerra, comenzaron a potenciar el cine documental como instrumento de propaganda. "La entrada en la guerra de Estados Unidos con la consiguiente avalancha mundial de su cine antialemán convenció al propio general Ludendorff, que exigió la unificación de las dispersas compañías nacionales. Así, en 1917 nació la UFA (Universum Film A.G.) dedicada a concentrar esfuerzos de propaganda, no solo bélica, sino también de la cultura alemana en el extranjero" (Romero, 2013).

\subsection{El caso específico del cine francés y americano durante la Gran Guerra}

En la primera década del siglo XX, se produjo en Francia un brillante comienzo del cine, a partir de que los hermanos Lumière iniciaran las primeras filmaciones de imágenes en movimiento. En estos preludios de la historia del cine, debutó el noticiario cinematográfico con el Pathé-Journal y el género histórico adquirió categoría con el llamado Film d'Art. Este auge del cine francés se detendría debido precisamente al estallido de la Guerra en beneficio del amplio despliegue del mercado norteamericano (Barros, 2013). Una vez iniciado el conflicto bélico, en Francia comenzaron a producirse algunos cortometrajes como "Mort au champ d'honeur" (Leonce Perret, 1914), "L'infirmiere" (Henri Pouctal, 1914), "Le polus de neuviéme" (Georges Rémond, 1915), La petite heroine" (Louis Paglieri, 1915) o "Les poilus de la revancha" (Leonce Perret, 1916).

En cuanto a Estados Unidos, en un principio se mantuvo un tanto alejado de cualquier compromiso con la guerra. Se pueden encontrar películas que evidencian esta clave imparcial, por ejemplo "Be neutral" (Francis Ford, 1914), así como filmes que representaban manifestaciones pacifistas: "Civilisation, or He who returned" (Thomas H. Ince, 1916), "War brides" (Herbert Brenon, 1916) o "Intolerance" (Griffith, 1916). Al mismo tiempo, también empezaron a aparecer películas intervencionistas en contra del gobierno de Wilson, que defendía la neutralidad y la paz. Son filmes que abogaban por un llamamiento a las armas, tales como "The glory of the nation" (Stuart Blackton, 1915) o "The Battle cry of peace" (Blackton, 1915).

Estados Unidos entró en guerra el 5 de abril de 1917. A partir de entonces el gobierno retiró de la circulación todas las películas pacifistas y los estudios cinematográficos se dedicaron a producir filmes en línea con la nación en guerra (Nepoti, 
1998: 231). De hecho, el Comité Federal de Información Pública pronto creó una división cinematográfica con fines propagandísticos, tanto en la producción de noticiarios, como en la ficción, en la que emergen numerosos filmes, algunos de ellos dirigidos por autores hasta entonces pacifistas y a quienes se les solicitó que apoyaran la guerra, como Griffith o Brenon.

\subsection{La Gran Guerra como argumento de la ficción cinematográfica}

Tanto desde América como desde Europa, la Gran Guerra ha servido a muchos directores como argumento de sus producciones cinematográficas. Desde Estados Unidos y Europa nos han llegado filmes sobre la contienda, realizados en diferentes épocas por varios directores: Milestone (1939); Borzage (1934); Kubrick (1957); Renoir (1937); Monicelli (1959); Lean (1962) y Carion (2005), entre otros.

También en la literatura científica ha quedado reflejada la contribución del cine a la narración de los acontecimientos de la I Guerra Mundial. Desde las clásicas obras de carácter histórico (Gubern, 1971; Pizarroso Quintero, 1998; Montero Díaz y Rebollo, 1998 y Romero, 2013) a artículos recogidos en revistas científicas (Coronado Ruiz, 2005; García Fernández y Sánchez González, 2001; Muñoz Suay, 2013). En el caso de las dos obras cinematográficas de referencia, hay algunas contribuciones fundamentales para entender la aportación de las dos obras analizadas: tanto la de Kubrick (Forner Muñoz, 1999; Ciment, 2000, Mágic, 2006), como la de Renoir (Flores Auñón, 1981; y Bazin 1973 y 1999).

\section{Metodología}

Para contextualizar la aportación de las dos obras analizadas en la ficción narrativa de la I Guerra Mundial, se ha partido de una técnica documental y de la lectura de algunas obras que han permitido elaborar un marco teórico sobre la aportación del cine a la reconstrucción cinematográfica de este conflicto bélico. Las diferentes lecturas han sido completadas con el análisis de la estructura, la temática y los personajes de las dos películas: "Senderos de gloria" y "La gran ilusión". Todo ello permitió elaborar las conclusiones que ponen de manifiesto la particular visión que Renoir y Kubrick tenían de la Gran Guerra.

\section{Dos miradas fílmicas a la I Guerra Mundial: "Senderos de Gloria" (Stanley Kubrick, 1957) y "La Gran Ilusión” (Jean Renoir, 1937)}

De todas las contribuciones cinematográficas sobre la Gran Guerra, se han elegido para este trabajo las miradas fílmicas antibelicistas que Stanley Kubrick y Jean Renoir hicieron en sus películas "Senderos de gloria" (Stanley Kubrick, 1957) y "La gran 
ilusión" (Jean Renoir, 1937). La biografía y el entorno ideológico (Flores Auñon, 1981 y García Fernández y Sánchez Gonzáles, 2001) de los dos directores marcan estas dos miradas complementarias de la contienda.

Kubrick es un director norteamericano, nacido en New York, concretamente en el Bronx. Aficionado a la fotografía y al jazz es un director meticuloso en el trabajo, con un estilo narrativo intrincado, sinuoso y mostrando siempre un control total de "producto artístico" de vanguardia y preocupado por los aspectos más autodestructivos de la condición humana. Por su parte, Renoir, nació en París y heredó de su padre el gusto por la pintura. Sus actividades y gustos estaban asociados directamente al universo del cine, como guionista y director escénico. Cuando realizó "La gran ilusión" ya simpatizaba con el Frente Popular y estaba en posiciones ideológicas de la izquierda. Dos directores, por tanto, con una tradición cultural y artística muy diferente, pero con un incuestionable prestigio.

Las dos películas elegidas para este análisis trascienden la propia materialidad del conflicto bélico narrado. Aunque ambos relatos sostienen una posición antibelicista, cada director lo hace con un tratamiento diferente. Kubrick exhibe una representación de la guerra en una galería de personajes, situaciones y detalles que muestran la crueldad y el horror sin paliativos. Su discurso se centra en gran medida en la evidencia de los hechos. Renoir también manifiesta una posición antibelicista, pero omite la realidad de los combates y se limita a sugerir una "gran ilusión" que admite diferentes lectura e interpretaciones, todas vinculadas con la endeblez de la naturaleza humana.

\subsection{La Gran Ilusión. Jean Renoir (1937)}

A diferencia de Kubrick, Renoir conocía la guerra de primera mano porque había servido en el ejército francés en tareas de reconocimiento de las líneas alemanas. La guerra, su aviación, el campo de prisioneros y las evasiones estaban en su recuerdo y fueron la base argumental de esta cinta. Con estos retazos elaboró el guión en colaboración con Charles Spaak.

Jean Renoir explica, en el trailer compuesto para el reestreno de 1958, cómo nació el film: "La historia de la Grande Illusion es rigurosamente cierta y me fue contada por varios de mis camaradas de guerra... En especial por Pinsard -Pinsard estaba en la aviación de caza y yo en una escuadrilla de reconocimiento. Tomaba fotos de las líneas alemanas y en varias ocasiones me salvó la vida interviniendo en el momento en que los cazas alemanes se mostraban demasiado pegajosos. El mismo fue derribado siete veces, hecho prisionero siete veces y se evadió siete veces. Sus fugas son la base de La Grande Illusion..." (Bazin, 1973: 54).

En la película, Renoir narra como un avión francés es abatido en el curso de una operación de reconocimiento y son hechos prisioneros sus dos tripulantes: Bö̈eldieu, de origen aristocrático y militar de carrera, y Maréchal, un teniente que ha 
ascendido por méritos. El capitán von Rauffenstein, un oficial germano aferrado a los viejos códigos de honor los acoge cortésmente en una fortaleza donde los capturados conocen a Rosenthal, hijo de un banquero judío y a varios personajes (un actor de teatro, un ingeniero y un profesor), representativos de los diversos estamentos de la Francia de aquella época. Al tiempo que organizan la fuga, Rauffenstein y Boïeldieu confraternizan debido a su similar origen social, al tiempo que Maréchal lo hace con su guardián alemán, hombre como él del pueblo. La acción transcurre en Alemania durante 1914-1918, en un campo de prisioneros para oficiales. No obstante, un preámbulo en el frente francés, abre la historia.

Con un tratamiento realista, el director ejecuta esta orquesta espacio-temporal que se estructura en tres partes con un punto de tensión (Gómez-Arteaga, 2008). Cada bloque describe una parte que corresponde al trayecto efectuado por Maréchal, desde el momento en que es capturado hasta que llega a la frontera suiza. Cada parte dispone de un espacio específico (Hallsbach, Wintersborn y la finca de Elsa), que unifican la acción con tres celebraciones diferentes: la fiesta teatral, el evento musical y la cena de Navidad.

La "Gran ilusión" es un relato abierto a múltiples miradas e interpretaciones. Unos se inclinan por entender la ilusión de la paz (Sadoul, 1991:255). Otros observan el refinamiento de los modos y maneras entre los oficiales de uno y otro bando como un signo de decrepitud.

A diferencia de Kubrick en "Senderos de gloria“, Renoir no muestra las atrocidades de la guerra, ni tampoco responde a los convencionalismos del cine de género bélico. Los lugares y escenarios no son los del frente: no se presentan trincheras, ni tampoco se percibe la angustia de los soldados, o el horror de la muerte en sus rostros. La acción transcurre con ritmo interno y parsimonia, en presidios para oficiales.

A Renoir no le interesa la guerra, sino sus consecuencias. Es otro discurso pacifista, menos visceral y emocional que el de Kubrick, más frío, distante, racional. "Es cierto que la consabida crueldad bélica queda amortiguada. El campo de Hallsbach parece un lugar de recreo. Está lejos de la imagen que tenemos de prisioneros, que es la de los campos de exterminio nazis en la II Guerra Mundial. Este es un campo de oficiales" (Gómez-Orteaga, 2009: 22).

Así pues, nos encontramos con un tratamiento, también realista, pero diferente al del director neoyorkino. La realidad de los combates se omite y se limita a mostrar los efectos. La apuesta de Renoir, más que condenar los horrores de la guerra, suscita la revisión del origen de la injusticia, mostrando las brechas y fisuras que existen en la propia naturaleza social, más allá de tiempos y fronteras. "Los dos vectores que mueven la obra de Renoir, el idealismo romántico y el progresismo social, aparecen fundidos en su generoso alegato pacifista: La gran ilusión" (Gubern, 1979: 324).

En definitiva, Renoir refleja los debates ideológicos que sacudieron al mundo intelectual francés en la segunda mitad de los años treinta. Un final abierto que abre 
una puerta a la esperanza en torno a las ilusiones de los humanos, truncadas por la Segunda Gran Guerra.

\subsection{Senderos de Gloria. Stanley Kubrick (1957)}

Como ocurre con "La gran ilusión" de Renoir, el film dispone de tres actos. El primero describe como los soldados franceses, en primera línea de fuego, reciben la orden de ocupar una colina imposible. La orden responde a la avaricia de un general, que observando como la derrota de sus tropas es inminente, ordena disparar contra sus propios hombres que se retiran ante la imposibilidad de avanzar: un general enfadado que dicta un consejo de guerra contra sus hombres, incapaz de reconocer su culpa. El segundo acto narra la elección al azar de tres hombres del regimiento francés para ser juzgados y ejecutados por cobardía ante las órdenes suicidas recibidas, bajo la cómplice mirada de sus compañeros. La última parte es la escena que marca una de las diferentes más notables con la novela. En ella, el general recibe el desprecio de unos hombres cansados de luchar a las órdenes de déspotas generales que dictan sus normas sentados en las mesas de sus despachos y trincheras, siempre protegidas de fuego enemigo.

Los dos escenarios en los que transcurre la acción son el cuartel general en el que se reúnen los generales y se celebra el juicio, y las trincheras, donde malviven los soldados. Con la descripción de estos escenarios comienza a manifestar el director un tratamiento del conflicto bélico notablemente diferente al exhibido por el director francés. Así como en "La gran ilusión" no se mostraban detalles - ni espacios, ni rostros que expresaran el dolor del horror de la guerra- con "Senderos de gloria" el director presenta dos universos opuestos. El primero, decorado a modo de un palacio, el cuartel general, casi siempre mostrado con la cámara a ras de suelo y en ligero contrapicado, subrayando la mayestática de los aposentos. En cambio, las trincheras son retratadas mediante continuos travellings que nos sitúan en el interior mismo de éstas, en las que impera la suciedad, desesperación y muerte. A lo largo de la cinta, Kubrick desliza nuestra mirada del alfombrado de larguísimos travellings versallescos de las suntuosas residencias de los mandos, hasta las oscuras y estrechas ratoneras de las trincheras, donde se hacinan los soldados. En síntesis, el mundo de los que mandan y de los que obedecen es mostrado con toda su crueldad.

La representación que realiza el director de "Senderos de gloria" retrata con detalle y plasticidad el engranaje de destrucción física, psicológica y moral de la guerra, a diferencia del cine de Renoir, en el que la guerra sólo es un trasunto para articular un discurso sobre grados y niveles de injusticia social. Así se percibe en la secuencia del ataque a la Colina de las Hormigas o en la ejecución, ante la prensa, de los prisioneros.

No obstante, Kubrick no se queda sólo en este primer nivel de denuncia, mostrativo y evidente. Al igual que "La gran ilusión", se trata de una película basada en hechos reales, documentada con precisión y verosimilitud, que plantea una profunda 
reflexión sobre el principio militar de la obediencia. El consejo de guerra al que se somete es un paródico esperpento en el que se mueven como marionetas los derechos humanos más fundamentales en los casos de guerra. Con un acusado realismo, como en Renoir, cada elemento de los que articulan el discurso bélico del film es un manifiesto antimilitar.

\section{Conclusiones}

La Primera Guerra Mundial ha servido como argumento de un importante número de obras cinematográficas, dando paso al cine belicista como género. Este conflicto bélico, conocido como la Gran Guerra, ha sido retratado con diferentes enfoques: desde el meramente propagandista al antimilitarista y antibelicista.

En las obras de Renoir y Kubrick que han sido analizadas -"La gran ilusión" y "Senderos de gloria" - el denomindador común es su declarado antibelicismo, aunque desde posiciones diferentes de cada director. En el caso de Renoir, la guerra es un instrumento del pasado al servicio de los poderosos en los que los más débiles son involucrados sin ser conscientes de ello. La guerra es el último recurso de una clase decadente que ostenta el poder, frente a las clases populares que quieren vivir en paz en vez de morir.

Algo parecido se proyecta en la obra de Kubrick. Los horrores de la guerra ponen de manifiesto cómo los hombres pueden generar unos acontecimientos que evidencian la deshumanización, la falsa apariencia y el desengaño, en el que las clases más populares y humildes no pueden alcanzar los objetivos que otros consiguen cuando ejercen su poder.

En todo caso, se trata de dos discursos contra la guerra. Uno realizado por Kubrick desde el horror de las trincheras y el otro llevado a cabo por Renoir, desde la reflexión y el debate ideológico de su militancia en la izquierda política.

\section{Bibliografía}

BAZIN, A (1999). Jean Renoir. Periodos, filmes, documentos. Buenos Aires: Paidós. --- (1973). Jean Renoir. Madrid: Artiach Editorial.

BARROS, S. (2013). "El cine Europeo. Cinco naciones en pugna. Francia, Inglaterra, Italia, Suecia y la URSS rivalizan con coproducciones de gran calidad". En: http://www.librosmaravillosos.com/historiacine/capitulo12.html

CIMENT, M. (2000). Kubrick: edición definitiva. Madrid: Akal.

CORONADO RUIZ, C. (2005). "La Primera Guerra Mundial en el cine italiano: la Gran Guerra. En: Historia y Comunicación Social, 10. p. 51-71.

COUSINS, M. (2008). Historia del cine. Madrid: Blume.

GUERRA GÓMEZ, A. y TAJAHUERCE, I. (1995). "La Primera Guerra Mundial: belicismo, pacifismo y antimilitarismo en el cine norteamericano". En: 
MONTERO DÍAZ, J. y PAZ REBOLLO, M. P. (eds.) (1995). Historia y cine: realidad, ficción y propaganda. Madrid: UCM. p. 47-68.

FAZIO, M. (2009). De Benedicto XV a Benedicto XVI. Madrid: Rialp.

FORNER MUÑOZ, S (1999). "La Primera Guerra Mundial según la visión de Stanley Kubrick en "Senderos de gloria". En: Uroz Sáez (Coord.). Historia y cine. Alicante: Espagrafic. p. 440-460.

FLORES AUÑON, J. C. (1981). "Cine y opción política: El cine del Frente Popular Francés". En: Cuadernos de Historia Moderna y Contemporánea, vol. 2.

GARCÍA FERNÁNDEZ, E y SANCHEZ GONZÁLEZ, S. (2001). "Las imágenes de la historia en la obra de Stanley Kubrick". En: Cuadernos de Historia Contemporánea, 23. p. 17-66.

GÓMEZ-ARTEAGA, G. (2008). “La guerra de guante blanco o la Gran Ilusión”. En: PABLO CONTRERAS, S. (2008), Universidad del País Vasco. Servicio Editorial. En: http://www.ehu.es/argitalpenak/images/stories/libros_gratuitos_en_pdf/ Humanidades $/ \mathrm{La} \% 20 \mathrm{Historia} \% 20 \mathrm{a} \% 20$ traves $\% 20$ del $\% 20$ cine. $\% 20 \overline{\mathrm{Las}} \% 20$ dos\%20guerras20mundiales.pdf

GUBERN, R. (1971). Historia del cine. Barcelona: Lumen.

HOWARD, M. (2003). La Primera Guerra Mundial. Barcelona: Crítica.

JEANNE, R. \& FORD, Ch. (1984). Historia ilustrada del cine. Madrid: Alianza Editorial.

KORTE, H. (1997). "La guerra y el cine: de Weihnachtsglocken (campanas navideñas) (1914) a Shoulder Arms (Armas al hombro) (1918)". En: FAULSTICH, WERNER \& KORTE (eds.) (1997). Cien años de cine 1895-1995. Desde su nacimiento hasta su establecimiento como medio. Madrid: Siglo XXI Editores. p. $350-371$.

LATHAM, J. (2006). "Technology and 'Reel Patriotism' in American Film Advertising of the World War I Era”. En: Film \& History: An Interdisciplinary Journal of Film and Television Studies, Vol. 36.1. p. 36-43.

MAGIC, E. (2006). "Senderos de gloria: Presentación del filme "Senderos de gloria" de Stanley Kubrick y claves para su uso en clase como herramienta educativa". En: Making of: cuadernos de cine y educación, 45. p. 28-33.

MONTERO DÍAZ, Julio y PAZ REBOLLO, María Antonia (eds.) (1995). Historia y cine: realidad, ficción y propaganda. Madrid: UCM.

MUÑOZ SUAY, R. (2013). "El cine y la I Guerra Mundial", Institut Valencià de l'Audiovisual i de la Cinematografia, Generalitat Valenciana. En: http://ivac.gva. es/efg1914/index.php/que-es-efg1914/el-cine-y-la-i-guerra-mundial/

NEPOTI, R. (1998). "Tradición documental y cine de propaganda". En: TALENS, J. \& ZUNZUNEGUI, S. (eds.) (1998). Historia General del Cine (Volumen III). Madrid: Cátedra. p. 213-242.

PIZARROZO QUINTERO, A. (1998). "Guerra, Cine e Historia. La guerra de 1898 en el cine". En: Historia y Comunicación Social, 3. p.143-162.

PORTER, M. \& GONZÁLEZ, P. (1988). Las claves de la historia del cine. Barcelona: Arín. 
QUIJANO RAMOS, D. (2011). "Las causas de la Primera Guerra Mundial". En: Revista Clases de Historia, 4.

RAMIREZ BENITO, P. (2010). "La Primera Guerra Mundial a través de "Los Aliados', un semanario antigermanófilo". En: Berceo, 159. p. 145-163.

ROMERO, E. (2013): La Primera Guerra Mundial y el cine. El refugio de los canallas. Madrid: T\&B Editores.

SADOUL, G. (1991). Historia del cine mundial. Madrid: Siglo XXI.

SANZ DÍAZ, F. (2009). "La Primera Guerra Mundial (1914-1918)". En: PEREIRA CASTAÑARES, J. (ed.). (2009). Historia de las relaciones internacionales contemporáneas. Madrid: Biblioteca Histórica Marqués de Valdecilla (UCM). p. 281-298.

TALENS, J. y ZUNZUNEGUI, S. (1998). Historia General del Cine (Volumen III). Madrid: Cátedra.

\section{Los autores}

Carmen Marta-Lazo es Profesora Titular de Comunicación Audiovisual y Publicidad de la Universidad de Zaragoza. Doctora en Ciencias de la Información por la Universidad Complutense de Madrid. Investigadora Principal del Grupo de Investigación en Comunicación e Información Digital (GICID). Responsable de Política universitaria y Foros científicos del Observatorio del Ocio y del Entretenimiento Digital (OCENDI). Es Secretaria de Redacción de la Revista Mediterránea de Comunicación y miembro del Comité Científico de Revista Latina, Enl@ce, Icono 14, ZER,@tic, Ámbitos, Pangea, Novarum, entre otras.

José Antonio Gabelas Barroso es Profesor Ayudante Doctor de Comunicación Audiovisual y Publicidad de la Universidad de Zaragoza. Doctor en Ciencias de la Información por la Universidad Complutense de Madrid. Diplomado en Cinematografía por la Universidad de Valladolid. Miembro del Grupo de Investigación en Comunicación e Información Digital (GICID). Ha sido Investigador de GIEC, Grupo de Investigación en Educomunicación de la Universidad San Jorge y es miembro del Grupo de Investigación CONINCOM, de Comunicación, Infancia y Conflicto de la Facultad de Ciencias de la Educación de la Universidad de Blanquerna de Cataluña.

Miguel Angel Ortiz Sobrino es Profesor Contratado Doctor de la Universidad Complutense de Madrid. Doctor en Ciencias de la Información por la Universidad Complutense de Madrid. Entre el año 2000 y 2009 ha dirigido el Instituto Oficial de Radio y Televisión. Ha dirigido, desde 1989 a 2009, el Master de Radio Universidad Complutense/RNE. Actualmente, es profesor del área de Empresa Informativa en la Universidad Complutense de Madrid y Delegado para Medialab/Inforadio de la Facultad de Ciencias de la Información de esa Universidad. 